\title{
Development of an Integrated Earthquake Early Warning System in Taiwan - Case for the Hualien Area Earthquakes
}

\author{
Yih-Min Wu ${ }^{1}$, Jen-Kuang Chung ${ }^{1}$, Tzaay-Chyn Shin ${ }^{1}$, Nai-Chi Hsiao ${ }^{1}$, Yi-Ben Tsai ${ }^{2}$, \\ William H. K. Lee ${ }^{3}$, and Ta-liang Teng ${ }^{4}$
}

(Manuscript received 28 June 1999, in final form 6 October 1999)

\begin{abstract}
In order to explore the feasibility of an earthquake early warning system for Taipei, two prototype seismic early warning systems have been implemented in Hualien, about 120 km away. The Taiwan Rapid Earthquake Information Release (TREIRS) can routinely determine earthquake location and magnitude in about one minute after the earthquake occurred. However, this reporting time is too long for earthquake early warning purposes. A dense, real-time monitoring system composed of 8 strong-motion stations was installed in Hualien area for testing earthquake early warning capability. For the 27 earthquakes occurred during August 1998 to April 1999, this system has successfully reported earthquake information in about $18 \mathrm{sec}$ after the origin time. Therefore, it provided about $15 \mathrm{sec}$ of early warning time before shear waves arrival in the Taipei urban area. Based on our experience of these two systems, we are encouraged to proceed forward in the development of an earthquake early warning system.
\end{abstract}

(Key words: Earthquake, Earthquake early warning, Real-time seismic system)

\section{INTRODUCTION}

Real-time seismic monitoring, especially for strong earthquakes, is an important tool for seismic hazard mitigation (Kanamori et al., 1997; Teng et al., 1997; Wu et al., 1997a). Recently, two real-time strong-motion networks have been installed in Taiwan by the Central Weather Bureau (CWB), Taipei. In order to improve the capability of these networks, early waming techniques are being developed.

Taiwan is located on the western Circum-Pacific seismic belt. The Philippine Sea plate subducts northward under the Eurasia plate along the Ryukyu trench. The Eurasia plate sub-

\footnotetext{
${ }^{1}$ Central Weather Bureau, 64 Kung Yuan Road, Taipei, Taiwan, ROC

${ }^{2}$ Institute of Geophysics, National Central University, Chung-li, Taiwan, ROC

${ }^{3} 862$ Richardson Court, Palo Alto, CA 94303, USA

${ }^{4}$ Department of Earth Sciences, University of Southern California, Los Angeles, CA, USA
} 
ducts eastward under the Philippine Sea plate off the southern tip of Taiwan. Most of Taiwan is under NW-SE compression with a measured convergence rate of about $7 \mathrm{~cm} / y e a r$. Many disastrous earthquakes have occurred in the past. Figure 1 is an epicentral map showing disastrous earthquakes in Taiwan during 1900 to 1999 . These earthquakes may be divided into two general classes: the earthquakes associated with the subduction of the Philippine Sea plate northward under the Eurasia plate (e.g., near and offshore of Hualien), and the ones associated with active faults in the western Taiwan.

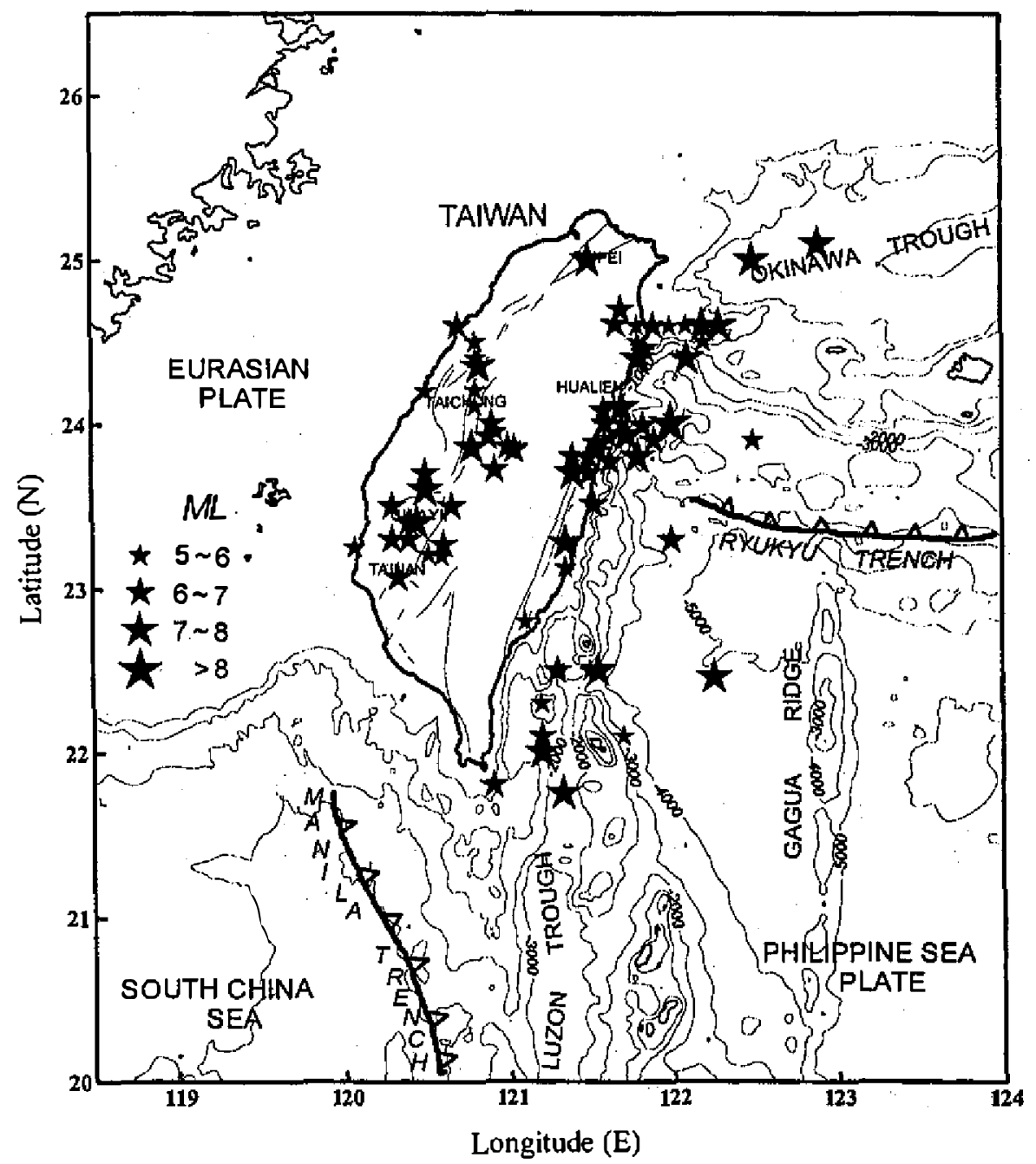

Fig. 1. Epicenter distribution of disastrous earthquakes during 1900 to 1999 in Taiwan area. These earthquakes may be divided into two general classes: the earthquakes associated with the subduction of the Philippine Sea plate northward under the Eurasia plate, and the ones associated with active faults in the western Taiwan. 
Early warning for earthquakes in western Taiwan is more difficult than the offshore earthquakes in eastem Taiwan because the earthquake sources are too close to the urban areas. However, the earthquakes near Hualien are quite different, and despite the distance, can cause severe damage in western Taiwan. An example is the 15 November, 1986 Hualien earthquake of $M_{L} 6.8\left(M_{w} 7.8\right)$. Although the epicenter was located near Hualien, the most severe damage occurred in the Taipei metropolitan areas on the western side of the island due to basin focusing effect (Yeh et al., 1988). The distance between Taipei and Hualien is about $120 \mathrm{~km}$, so that shear waves will take more than $30 \mathrm{sec}$ to reach Taipei. Thus, if a seismic monitoring system can issue an earthquake notification in less than $30 \mathrm{sec}$, earthquake early warning can be feasible in the populated Taipei area.

Plan A, a project to implement an earthquake early waming system in Taiwan, was first proposed by W. H. K. Lee at a meeting in December 1990. The CWB Advisory Committee approved this project in June 1992. At the January 1993 Advisory Committee Meeting of the CWB, Plan B was introduced by T. L. Teng. Both plans were put forward for real-time seismic monitoring with earthquake early waming in mind. Plan A is an experimental system exploring the technology of earthquake early warning for the highly seismic area of Hualien (Fig. 2) (Chung et al., 1995; Lee et al., 1995, 1996). Plan B is a rapid reporting system using a telemetered network of digital accelerographs distributed over the entire island (Shin et al., 1996; Teng et al., 1997; Wu et al., 1997a, 1997b).
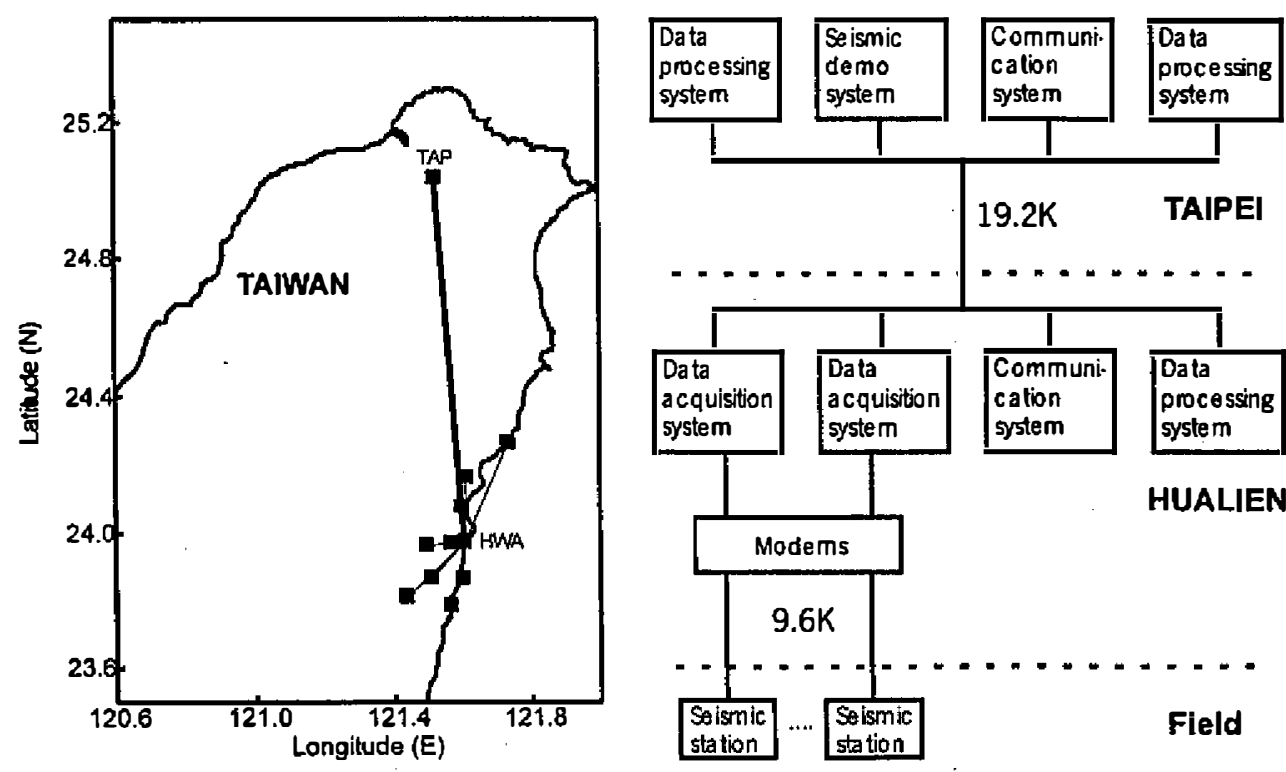

Fig. 2. The prototype earthquake early warning system in Hualien (Plan A). This system consists of 10 three-component accelerometers telemetered digitally via 9600-baud telephone lines to the CWB Hualien Station. At the Hualien Station, the incoming digital signals are processed in real time and the results are telemetered to the CWB Headquarters in Taipei. 
These two prototype seismic early warning systems were implemented by 1994. After four-years of field operation, Plan A system was phased out in 1998. Because the seismic array was small, there were large uncertainties on the determination of source parameters, although it produced good results for earthquakes very near Hualien. Plan B system was successfully operated for real-time seismic monitoring, especially for felt earthquakes. It has achieved simultaneous determination of earthquake location and magnitude about in one minute after the occurrence of a felt earthquake (Teng et al., 1997), and was named "Taiwan Rapid Earthquake Information Release System, TREIRS" (Wu et al., 1997a, 1997b).

In 1997, we began to establish a sub-network at Hualien area under the framework of TREIRS for development of earthquake early warning capability. In 1998, the stations of the Plan A were replaced by digital accelerographs with digital data output, and were merged into the TREIRS Hualien sub-network system. Due to addition of Plan A stations, we have obtained better source parameters and faster reporting times for earthquakes near Hualien. In this paper, we will evaluate the results from the three development stages of the Hualien experimental earthquake early warning system in eastern Taiwan.

\section{PLAN A: HUALIEN EXPERIMENTAL EARTHQUAKE EARLY WARNING SYSTEM}

The Hualien experimental earthquake early waming system is a prototype system, which was implemented in Hualien area to explore the use of modern technology for earthquake early-warning purposes. This system consisted of 10 three-component accelerometers (distributed in an aperture of about $20 \mathrm{~km}$ ) which were telemetered digitally via 9600-baud telephone lines to the CWB Hualien Station. At the Hualien Station, the incoming digital signals are processed in real time and the results are telemetered to the CWB Headquarters in Taipei (Fig. 2). One of the computers in Hualien handles the communication with Taipei via a dedicated telephone line (19.2k baud). A parallel computer system in Taipei is used for displaying, processing, and analyzing the received data. It also allows operators in Taipei to access, manage, and control the system in Hualien.

Nanometrics (a Canada-based commercial company) implemented both the hardware and software under the CWB specifications and direction. The goal was to detect, locate and transmit the source information to Taipei within $10 \mathrm{sec}$ after the occurrence of a strong earthquake in Hualien. This information could then be disseminated in Taipei prior to the arrival of the strong ground shaking (Chung et al., 1995, Lee et al., 1995; 1996). During the period from May 1994 to October 1994, thirty-two earthquakes with magnitudes ranging from 3.1 to 6.5 (Table 1) were detected. The performance of this system is analyzed in the following.

\subsection{Reporting time}

Two definitions of "response time" and "effective response time" are used. The "response time" is defined to be the duration from an earthquake origin time to the system reporting time. The "effective response time" is defined as the time between the first $P$ arrival to the nearest 
Table 1. Parameters of thirty-two events recorded by the Plan A system determined from on-line and off-line procedures, during the period from May 1994 to October 1994, with magnitudes ranging from 3.1 to 6.5

\begin{tabular}{|c|c|c|c|c|c|c|c|c|c|c|c|}
\hline \multirow{2}{*}{ Date } & \multirow{2}{*}{ Time } & \multicolumn{4}{|c|}{ Off-line (automatic) } & \multicolumn{4}{|c|}{ On-line (manual) } & \multirow{2}{*}{$\begin{array}{l}\mathrm{Tr}^{* *} \\
(\mathrm{sec})\end{array}$} & \multirow{2}{*}{$\begin{array}{l}\text { Ter** } \\
\text { (sec) }\end{array}$} \\
\hline & & $\overline{\text { Lat. }(\mathrm{N})}$ & $\mid \overline{\text { Long. (E) }}$ & $\begin{array}{l}\text { Depth } \\
(\mathrm{km})\end{array}$ & $\overline{\mathrm{M}_{\mathrm{t}}}$ & $\overline{\text { Lat. }(\mathrm{N})}$ & $|\overline{\text { Long (E) }}|$ & $\begin{array}{c}\text { Depth } \\
(\mathrm{km})\end{array}$ & $\overline{M_{L}}$ & & \\
\hline $1994 / 05 / 06$ & $17: 32: 45.81$ & 23.91 & 121.86 & 45.80 & 3.36 & 24.02 & 121.59 & 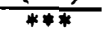 & $\overline{4.78}$ & 13 & 10 \\
\hline $1994 / 05 / 11$ & $05: 46: 59.80$ & 23.61 & 121.62 & 26.93 & 3.33 & 23.83 & 121.50 & & 4.20 & 11 & 10 \\
\hline $1994 / 05 / 13$ & 05:37:59.91 & 23.58 & 121.62 & 26.73 & 4.25 & 23.81 & 121.48 & & 5.04 & 12 & 11 \\
\hline $1994 / 05 / 16$ & $17: 51: 39.33$ & 24.12 & 121.57 & 30.46 & 3.93 & 24.02 & 121.75 & & 4.75 & 13 & 10 \\
\hline $1994 / 05 / 16$ & $20: 09: 51.14$ & 23.93 & 121.84 & 44.57 & 3.66 & 24.03 & 121.74 & & 4.22 & 13 & 10 \\
\hline $1994 / 05 / 16$ & $20: 52: 08.91$ & 23.83 & 121.77 & 51.07 & 4.43 & 23.87 & 121.93 & & 5.20 & 16 & 10 \\
\hline $1994 / 05 / 20$ & 03:01:37.95 & 24.46 & 121.80 & 7.55 & 3.81 & 24.07 & 121.44 & & 3.91 & 14 & 11 \\
\hline $1994 / 05 / 20$ & $16: 19: 24.65$ & 24.34 & 121.60 & 22.20 & 3.16 & 24.22 & 121.67 & & 4.30 & 13 & 12 \\
\hline $1994 / 05 / 24$ & 09:24:17.56 & 23.95 & 121.47 & 15.80 & 3.09 & 23.87 & 121.59 & & 4.37 & 15 & 11 \\
\hline $1994 / 05 / 27$ & $00: 54: 08.51$ & 24.04 & 121.74 & 60.12 & 3.09 & 24.00 & 121.76 & & 3.57 & 13 & 10 \\
\hline $1994 / 05 / 28$ & $17: 56: 36.70$ & 24.13 & 121.88 & 22.43 & 4.00 & 24.14 & 121.80 & & 4.86 & 14 & 10 \\
\hline $1994 / 05 / 29$ & 13:04:04.18 & 23.94 & 121.48 & 17.04 & 3.70 & 23.93 & 121.47 & & 4.72 & 12 & 10 \\
\hline $1994 / 05 / 30$ & $07: 50: 51.89$ & 24.08 & 121.58 & 16.98 & 4.51 & 23.79 & 121.56 & & 5.36 & 16 & 11 \\
\hline $1994 / 05 / 31$ & $13: 17: 27.74$ & 24.26 & 121.73 & 45.75 & 3.79 & 24.12 & 121.80 & & 4.40 & 15 & 12 \\
\hline $1994 / 06 / 04$ & 04:21:32.86 & 24.26 & 121.99 & 13.55 & 4.21 & 24.27 & 121.99 & & 5.14 & 21 & 16 \\
\hline $1994 / 06 / 05$ & 01:09:30.09 & 24.46 & 121.84 & 5.30 & 6.50 & 24.18 & 121.79 & & 5.68 & 18 & 11 \\
\hline $1994 / 06 / 05$ & 01:26:08.22 & 24.45 & 121.83 & 4.06 & 3.91 & 24.42 & 121.53 & & 4.90 & 20 & 15 \\
\hline 1994/06/05 & 01:34:05.56 & 24.48 & 121.83 & 5.86 & 3.53 & 24.27 & 121.73 & & 4.15 & 13 & 10 \\
\hline 1994/06/05 & $01: 37: 57.56$ & 24.49 & 121.81 & 6.29 & 3.64 & 24.17 & 122.04 & & 4.94 & 19 & 14 \\
\hline $1994 / 06 / 05$ & 01:59:05.43 & 24.45 & 121.72 & 11.65 & 3.62 & 24.16 & 121.58 & & 3.86 & 13 & 11 \\
\hline $1994 / 06 / 05$ & 02:04:01.90 & 24.46 & 121.74 & 8.87 & 3.72 & 24.24 & 121.61 & & 3.97 & 17 & 16 \\
\hline $1994 / 06 / 05$ & $02: 18: 22.30$ & 24.47 & 121.84 & 5.51 & 4.82 & 24.28 & 121.70 & & 5.12 & 18 & 16 \\
\hline $1994 / 06 / 05$ & $02: 25: 04.14$ & 24.46 & 121.88 & 5.35 & 3.99 & 24.28 & 121.83 & & 5.05 & 21 & 15 \\
\hline 1994/06/05 & 04:49:54.71 & 24.44 & 121.77 & 2.50 & 4.54 & 24.27 & 121.73 & & 5.73 & 13 & 13 \\
\hline $1994 / 06 / 05$ & 04:59:38.52 & 24.42 & 121.81 & 1.04 & 5.02 & 24.69 & 121.70 & & 5.41 & 18 & 16 \\
\hline $1994 / 06 / 05$ & $05: 51: 43.02$ & 24.46 & 121.91 & 4.99 & 4.83 & 24.27 & 121.73 & & 5.44 & 19 & 16 \\
\hline $1994 / 06 / 11$ & $16: 50: 17.65$ & 24.46 & 121.76 & 5.67 & 4.72 & 24.27 & 121.73 & & 4.99 & 18 & 16 \\
\hline $1994 / 06 / 17$ & $21: 13: 09.25$ & 23.91 & 121.53 & 18.34 & 3.86 & 23.98 & 121.55 & & 4.90 & 12 & 11 \\
\hline $1994 / 06 / 22$ & $22: 59: 11.18$ & 23.93 & 121.52 & 18.85 & 3.79 & 23.87 & 121.59 & & 5.51 & 16 & 15 \\
\hline $1994 / 07 / 26$ & $15: 18: 49.41$ & 23.69 & 121.43 & 1.30 & 4.53 & 23.72 & 121.37 & & 5.26 & 13 & 10 \\
\hline $1994 / 07 / 27$ & $10: 38: 27.85$ & 24.09 & 121.75 & 26.68 & 4.93 & 24.19 & 121.60 & & 5.57 & 16 & 11 \\
\hline $1994 / 10 / 05$ & 05:00:33.67 & 23.74 & 121.57 & 12.83 & 4.38 & 23.60 & 121.56 & & 5.03 & 16 & 12 \\
\hline
\end{tabular}

station and the system reporting time. Basically, the response time is defined from the seismological point of view; whereas, the effective response time is more suitable for assessing the system performance, since there is no seismic signal available to process until the first $P$ wave arrived at the nearest station. For Plan A system the response time varies from 11 to $21 \mathrm{sec}$ for the thirty-two earthquakes listed in Table 1, with an average of $15 \mathrm{sec}$ and a standard deviation of $3 \mathrm{sec}$. Effective response time of these earthquakes varies from 10 to $16 \mathrm{sec}$ with an average of $12 \mathrm{sec}$ and a standard deviation of $2 \mathrm{sec}$. The response time variation is generally larger 
than the effective response time, because deeper and further earthquakes occurred from the network will lead to larger response times. According to these two parameters, we find that this system can report earthquake information within about $20 \mathrm{sec}$ after an earthquake has occurred and within about $15 \mathrm{sec}$ after the first $\mathrm{P}$ arrival at the nearest station.

\subsection{Location}

As a comparison, epicenters of thirty-two earthquakes in Table 1 as determined by this system versus the manual locations are shown in Fig. 3. The average difference in epicenter location is about $22 \mathrm{~km}$ with a standard deviation $12 \mathrm{~km}$. This system did not determine the focal depth, because deeper earthquakes are less likely to cause severe damage. The epicenter determinations are poor because of an inadequate automatic phase picker software and a very small station coverage.

\subsection{Magnitude}

A good magnitude determination requires a reliable earthquake location. Unfortunately, the precision of epicenter determination by this system is poor. We use all the data for comparing the on-line determined magnitudes with the manually determined ones. The result is listed in Table 1. An overestimation of about 0.7 unit of magnitude is shown by the on-line system. The standard deviation is 0.5 of magnitude unit.

\section{PLAN B: HUALIEN SUB-NETWORK (I) OF THE TREIRS}

TREIRS was implemented using the existing telecommunication facilities of the Central Weather Bureau Seismic Network (CWBSN, with 75 short-period, 3-component seismic stations). CWBSN uses only half of the bandwidth of 9600-baud telephone lines for telemetry. Thus the remaining half of the bandwidth of 9600-baud telephone liness can be utilized to telemeter the co-sited strong motion data to the CWB Headquarters without an increase in operational costs. With the availability of digital accelerographs capable of digital data stream output and the IASPEI real time seismic monitoring software (Lee, 1994), CWB implemented a real-time, regional, telemetered strong-motion network for earthquake information rapid reporting. Through previous studies (Teng et al., 1997; Wu et al., 1997a; 1998a; Wu, 1999), we concluded that using a dense sub-network under TREIRS is a good approach to shorten the effective reporting time, and thus gaining some earthquake early warning capabilities.

The Hualien sub-network (I) of Plan B consists of 16 stations. The incoming signals are juxtaposed with TREIRS in CWB Headquarters in Taipei (Fig. 4). Learning from the experience of the Plan A system that a small station coverage can cause large location uncertainty (Wu et al., 1998b), this sub-network has a much larger station coverage than the Plan A system (Wu et al., 1998d). A digitization rate of 50 sps with 3 channels and 16-bit resolution was configured for each station in order to utilize the remaining 4800-baud of the CWB telephone lines. The recording range is from $-2 \mathrm{~g}$ to $+2 \mathrm{~g}$. The incoming data are pre-processed by a software program called XRTPDB published by IASPEI (Tottingham and Mayle, 1994). 


\section{Plan A Hualien Prototype System(94/05-94/10)}

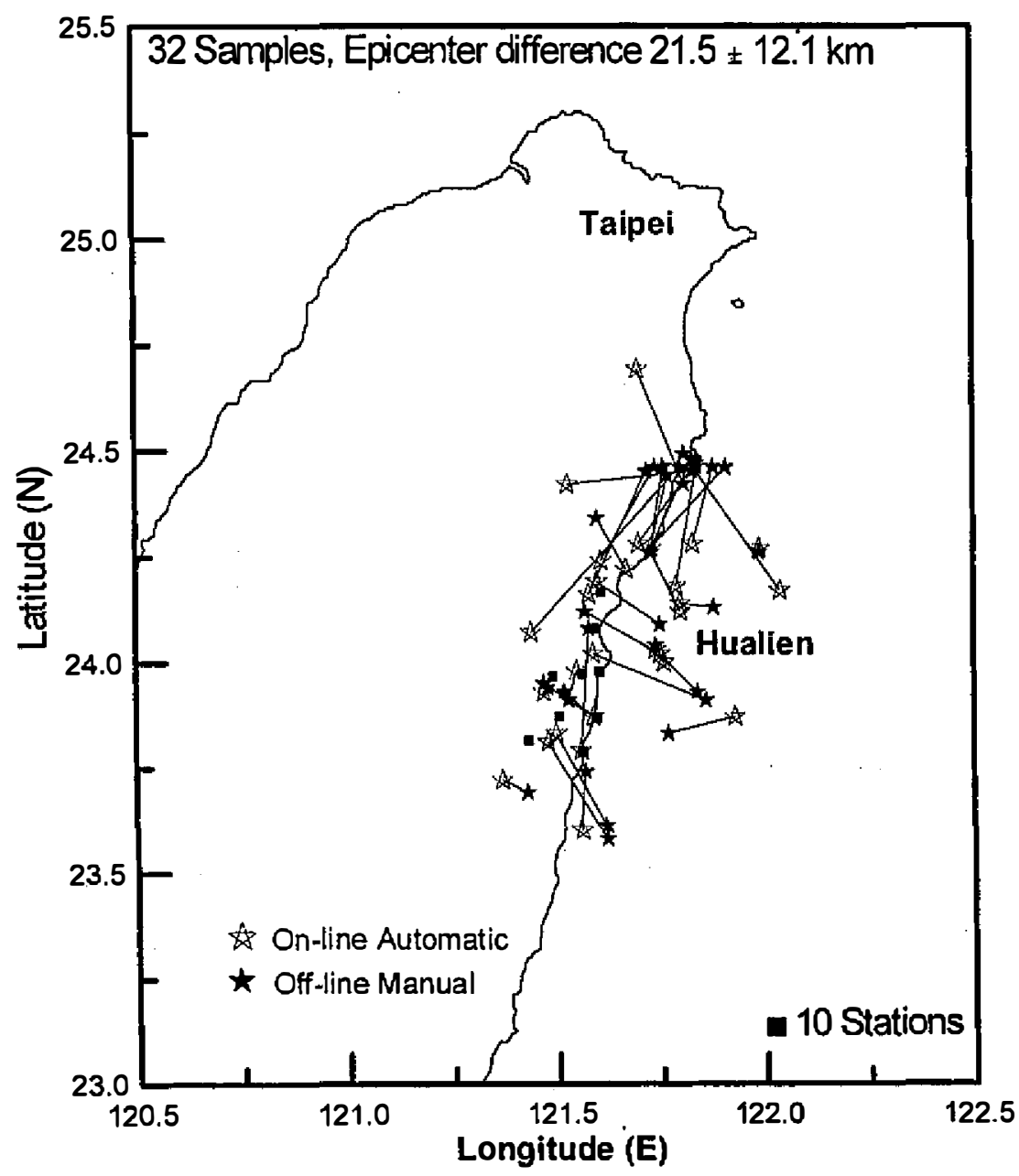

Fig. 3. Comparison of the automatic location and the manual location determined by Plan A system. The small solid squares are present the station location of this network.

Whenever the pre-specified trigger criteria are met, the digital waveforms will be continuously recorded for $8 \mathrm{sec}$. Then the digital waveforms are stored in memory and are automatically analyzed by a series of programs (Wu et al., 1998b).

Results are disseminated by two different ways: (1) through e-mail to inform the system manager, (2) through Microsoft Windows' WINPOPUP function to notify the CWB staff. Over an experimental period from July 1997 to February 1998, twenty-two earthquakes were recorded and processed. The recorded earthquakes with magnitudes, ranging from 3.7 to 5.5 , are too small to give actual early wamings. However, these earthquakes are still very useful for assessing the performance of this system. 


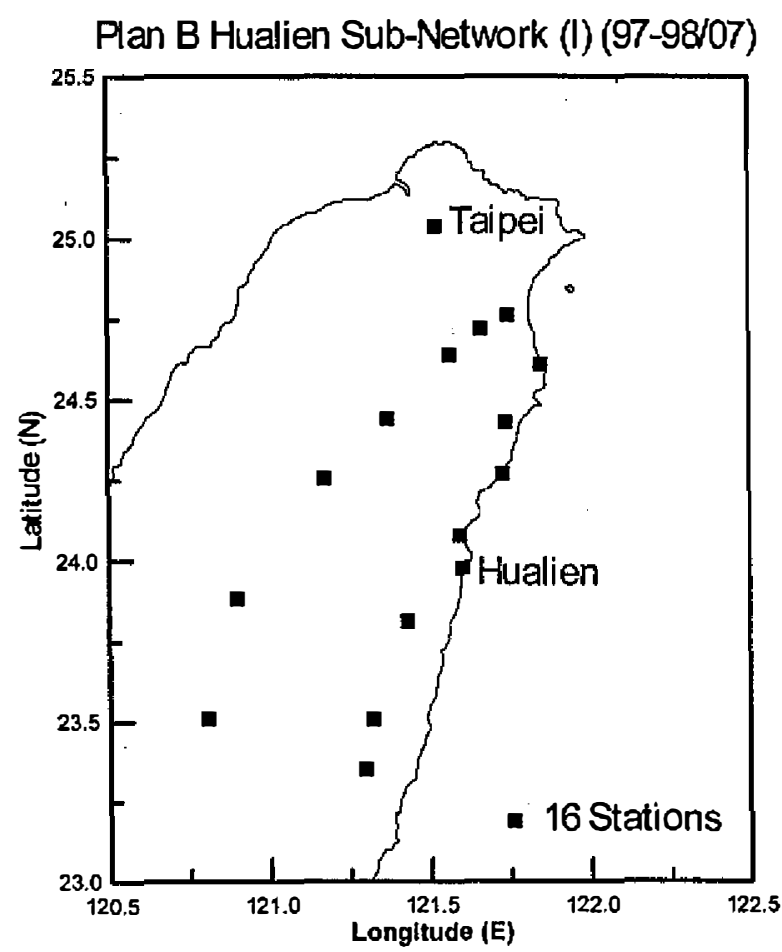

Fig. 4. Station distribution of the Plan B Hualien sub-network (I).

\subsection{Reporting time}

The response time of twenty earthquakes listed in Table 2 varies from about 14 to $24 \mathrm{sec}$. Their average is $18.5 \mathrm{sec}$ with a standard deviation of $2.5 \mathrm{sec}$. The effective response time varies from 10 to $17 \mathrm{sec}$. Their average is $14 \mathrm{sec}$ with a standard deviation of $2 \mathrm{sec}$. Generally, this system will be triggered at $2 \sim 3 \mathrm{sec}$ after the nearest station received the $P$ arrival, then signals are recorded continuously for about $8 \mathrm{sec}$, this plus a $3 \sim 4 \mathrm{sec}$ processing time, will give the effective response time. Accordingly, this system can report earthquake information within about $20 \mathrm{sec}$ after an earthquake has occurred. The reporting time is slightly longer than that for the Plan A system.

\subsection{Location}

As a comparison, the epicenters and focal depths of 22 earthquakes in Table 2, as determined by this system versus manual location are shown in Fig. 5 . The average difference in epicenter location is about $8 \mathrm{~km}$ with a standard deviation of $9 \mathrm{~km}$, and the average difference in focal depth is about $2 \mathrm{~km}$ with a standard deviation of $5 \mathrm{~km}$. These results are close to the TREIRS reported results (Wu et al., 1997a; 1997b; Lee et al., 1997; Wu, 1999), and these results are significantly better than those in the Plan A system. But in cases involved in early warning applications, these errors are tolerable because they are smaller than the source dimensions of a large earthquake. 
Table 2. Parameters of twenty-two events recorded by the Plan B Hualien subnetwork (I) determined from on-line and off-line procedures, during the period from July 1997 to February 1998, with magnitudes ranging from 3.7 to 5.5 .

\begin{tabular}{|c|c|c|c|c|c|c|c|c|c|c|c|}
\hline \multirow{2}{*}{ Date } & \multirow{2}{*}{ Time } & \multicolumn{4}{|c|}{ Off-line (manual) } & \multicolumn{4}{|c|}{ On-line (automatic) } & \multirow{2}{*}{$\begin{array}{c}\mathrm{Tr} \\
(\mathrm{sec})\end{array}$} & \multirow{2}{*}{$\begin{array}{c}\text { Ter } \\
\text { (sec) }\end{array}$} \\
\hline & & Lat. (N) & Long. (E) & $\begin{array}{c}\text { Depth } \\
(\mathrm{km})\end{array}$ & $M_{L}$ & Lat. $(\mathrm{N})$ & Long. (E) & $\begin{array}{c}\overline{\text { Depth }} \\
(\mathrm{km})\end{array}$ & $\mathrm{M}_{\mathrm{L}}$ & & \\
\hline $97 / 08 / 1 \mathrm{I} \#$ & $13: 25: 57 . \overline{85}$ & 24.06 & 121.49 & 26.72 & 4.33 & 24.04 & 121.51 & 28.32 & 4.43 & $-\cdots$ & -- \\
\hline 97/08/20\# & 07:12:04.86 & 24.23 & 120.95 & 32.52 & 4.71 & 24.21 & 120.98 & 26.31 & 4.60 & -- & .. \\
\hline $97 / 10 / 22$ & 19:01:51.22 & 24.13 & 121.89 & 48.27 & 4.79 & 24.12 & 121.82 & 52.84 & 4.48 & 18 & 10 \\
\hline $97 / 10 / 31$ & $23: 08: 35.73$ & 24.73 & 121.75 & 12.01 & 3.71 & 24.74 & 121.76 & 11.64 & 3.71 & 14 & 11 \\
\hline $97 / 11 / 07$ & $10: 19: 25.65$ & 24.13 & 121.90 & 49.5 & 4.49 & 24.21 & 121.69 & 36.84 & 4.32 & 20 & 13 \\
\hline $97 / 11 / 12$ & $22: 36: 48.38$ & 24.19 & 121.67 & 8.73 & 4.92 & 24.18 & 121.70 & 14.12 & 4.69 & 15 & 12 \\
\hline $97 / 11 / 13$ & $14: 12: 52.32$ & 24.21 & 121.62 & 4.23 & 3.69 & 23.99 & 121.91 & 14.53 & 4.25 & 19 & 16 \\
\hline $97 / 11 / 14$ & $04: 29: 54.36$ & 24.19 & 121.70 & 6.71 & 5.50 & 24.18 & 121.72 & 9.03 & 4.94 & 15 & 12 \\
\hline $97 / 11 / 17$ & $04: 58: 56.68$ & 24.14 & 121.66 & 9.07 & 4.14 & 24.17 & 121.61 & 11.58 & 3.99 & 17 & 14 \\
\hline $97 / 11 / 19$ & $03: 31: 13.85$ & 23.80 & 121.74 & 31.39 & 4.88 & 23.86 & 121.60 & 40.82 & 4.53 & 20 & 12 \\
\hline $97 / 11 / 23$ & $16: 04: 10.80$ & 24.19 & 121.59 & 10.45 & 4.08 & 24.20 & 121.56 & 10.22 & 4.12 & 21 & 17 \\
\hline $97 / 11 / 24$ & $03: 47: 10.22$ & 23.82 & 121.70 & 17.50 & 4.70 & 23.89 & 121.58 & 27.35 & 4.22 & 17 & 12 \\
\hline $97 / 12 / 09$ & $21: 39: 26.65$ & 24.45 & 121.89 & 16.58 & 4.56 & 24.46 & 121.87 & 15.63 & 4.38 & 19 & 15 \\
\hline $97 / 12 / 15$ & $16: 26: 47.64$ & 24.63 & 121.81 & 6.72 & 3.94 & 24.63 & 121.80 & 2.40 & 3.86 & 16 & 14 \\
\hline $97 / 12 / 21$ & $14: 52: 22.03$ & 24.42 & 121.91 & 10.81 & 4.23 & 24.39 & 121.96 & 13.92 & 4.29 & 19 & 15 \\
\hline $98 / 01 / 05$ & $14: 43: 30.20$ & 23.87 & 121.49 & 17.78 & 3.69 & 23.95 & 121.38 & 19.43 & 4.04 & 17 & 12 \\
\hline $98 / 01 / 15$ & $02: 12: 48.41$ & 24.82 & 121.98 & 7.22 & 4.47 & 24.76 & 121.95 & 12.72 & 4.25 & 21 & 16 \\
\hline $98 / 01 / 23$ & $22: 20: 37.03$ & 24.35 & 122.06 & 6.81 & 4.58 & 24.36 & 122.08 & 5.00 & 4.43 & 24 & 17 \\
\hline $98 / 02 / 03$ & $03: 21: 20.47$ & 24.04 & 121.49 & 20.56 & 4.11 & 24.09 & 121.41 & 17.72 & 4.12 & 19 & 14 \\
\hline $98 / 02 / 07$ & $07: 21: 38.62$ & 23.64 & 121.43 & 7.03 & 4.65 & 23.65 & 121.41 & 8.72 & 4.35 & 17 & 13 \\
\hline $98 / 02 / 24$ & 06:45:33.79 & 24.39 & 121.68 & 27.16 & 4.84 & 24.35 & 121.70 & 32.5 & 4.88 & 22 & 17 \\
\hline $98 / 02 / 24$ & $06: 59: 47.58$ & 24.39 & 121.67 & 28.08 & 4.75 & 24.40 & 121.69 & 30.9 & 4.69 & 20 & 15 \\
\hline
\end{tabular}

\# Testing period did not record reporting time

\subsection{Magnitude}

A prerequisite for good magnitude determination is to have a reliable earthquake location, thus seventeen earthquakes with location difference smaller than $15 \mathrm{~km}$ in Table 2 are selected for comparing the magnitude difference between the on-line automatic solutions and the offline manual results. As shown in Fig. 6, the differences between the on-line and off-line magnitude procedures have an average of 0.1 unit with a standard deviation of 0.2 unit. The on-line determined magnitudes are smaller than the off-line values, especially for earthquake magnitude larger than 4.25 . When the system was triggered by a large earthquake, the continuous recording time of $8 \mathrm{sec}$ may not be long enough for the shear wave trains to be recorded completely at distant stations. Although those stations would offer $\mathrm{P}$ arrivals for location, they would underestimate the magnitude value. However, there exists a linear relationship between magnitudes determined from on-line and off-line procedures as given by our previous study (Wu et al., 1998c). After the linear correction, the magnitude difference can be limited within 0.3 unit. Magnitude determination of this network is significantly better than that of the Plan A system. 


\section{Plan B Hualien Sub-Network (I)}

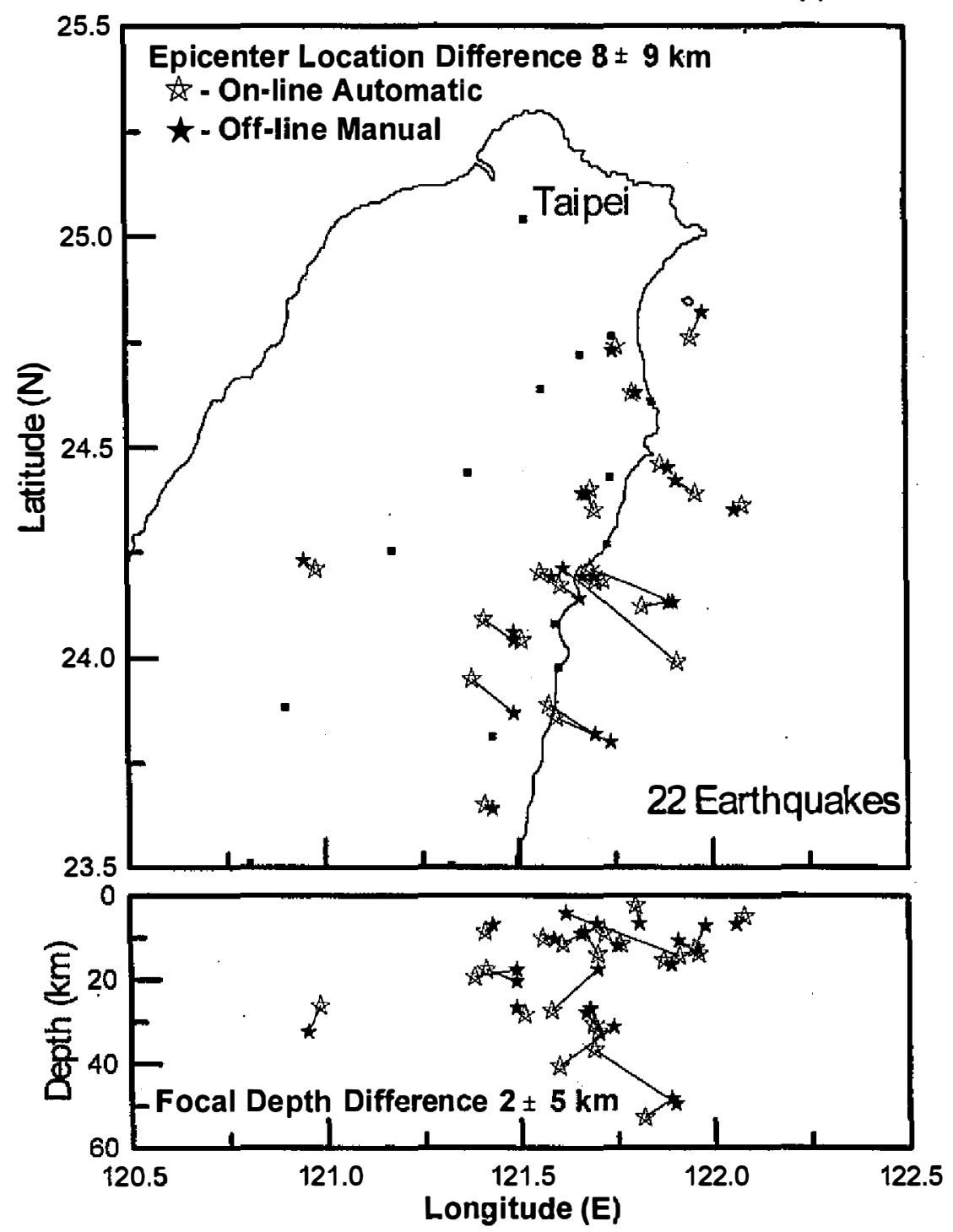

Fig. 5. Comparison of the automatic location and the manual location determined by the Plan B Hualien sub-network (I). The small solid squares are present the station location of this network.

\section{PLAN B: HUALIEN SUB-NETWORK (II) OF THE TREIRS}

Although the Plan B Hualien sub-network (I) performs significantly better in location and magnitude determination than the Plan A system, the Plan A system gives a quicker reporting time. There still exists some problems in these two systems: (1) The Plan A system gives large 


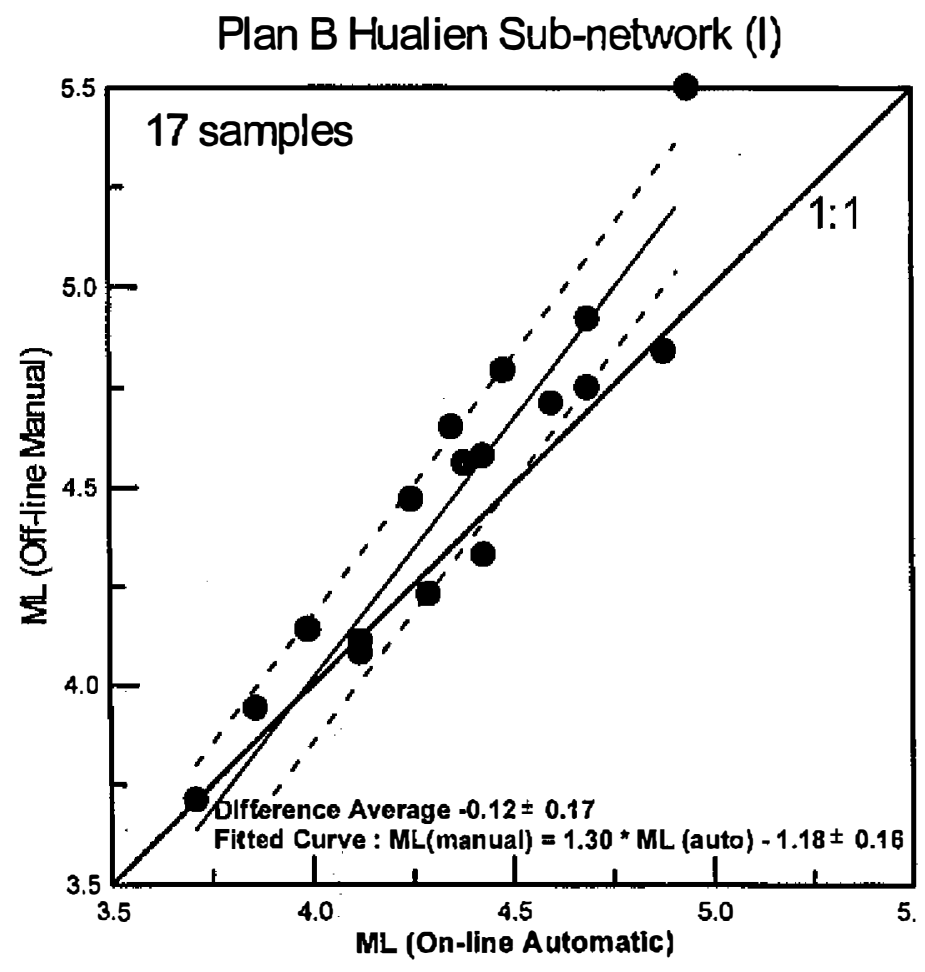

Fig. 6. Relationship between the automatic- determined magnitude and the manual-determined magnitude for seventeen events recorded by the Plan B Hualien sub-network (I). The on-line determined magnitudes are smaller than the off-line values, especially for earthquake magnitude larger than 4.25 .

uncertainty of source parameter determinations caused by small station coverage, unsuitable automatic phase picker software, and using $\mathrm{P}$ wave signals in determining the magnitude. (2) Plan A uses commercial software, which performs faster in communication and data processing functions. But it is difficult to modify the system configuration and add user-defined functions. (3) For monitoring earthquakes in the Hualien, the Plan B Hualien sub-network (I) station coverage is too low. Thus, the magnitude determination is smaller than that from the offline procedure (about $10 \mathrm{sec}$ after earthquake occurred, stations more than $40 \mathrm{~km}$ away do not record enough shear waves for determining magnitude). If more dense station coverage in the Hualien sub-net can be achieved, the magnitude determination will be better estimated.

Considering the above problems, we decided to phase-out the Plan A system, and combined the Plan A stations with the Plan B Hualien sub-network in 1998. With that we have reorganized a new integrated network. The "Plan B Hualien sub-network (II)" consists of 16 stations (Fig. 7) with high-density station coverage in the Hualien, and lesser density outside Hualien. From August 1998 to April 1999, twenty-seven earthquakes with magnitude ranging from 3.6 to 5.2 (Table 3 ) were recorded and processed. The performance of this system is shown below.

\subsection{Reporting time}

Response time of the twenty-seven earthquakes listed in Table 3 varies from about 14 to $25 \mathrm{sec}$. Their average is $18 \mathrm{sec}$ with a standard deviation of $3 \mathrm{sec}$. The effective response time of these earthquakes varies from 11 to $17 \mathrm{sec}$, their average is $13 \mathrm{sec}$ with a standard deviation 


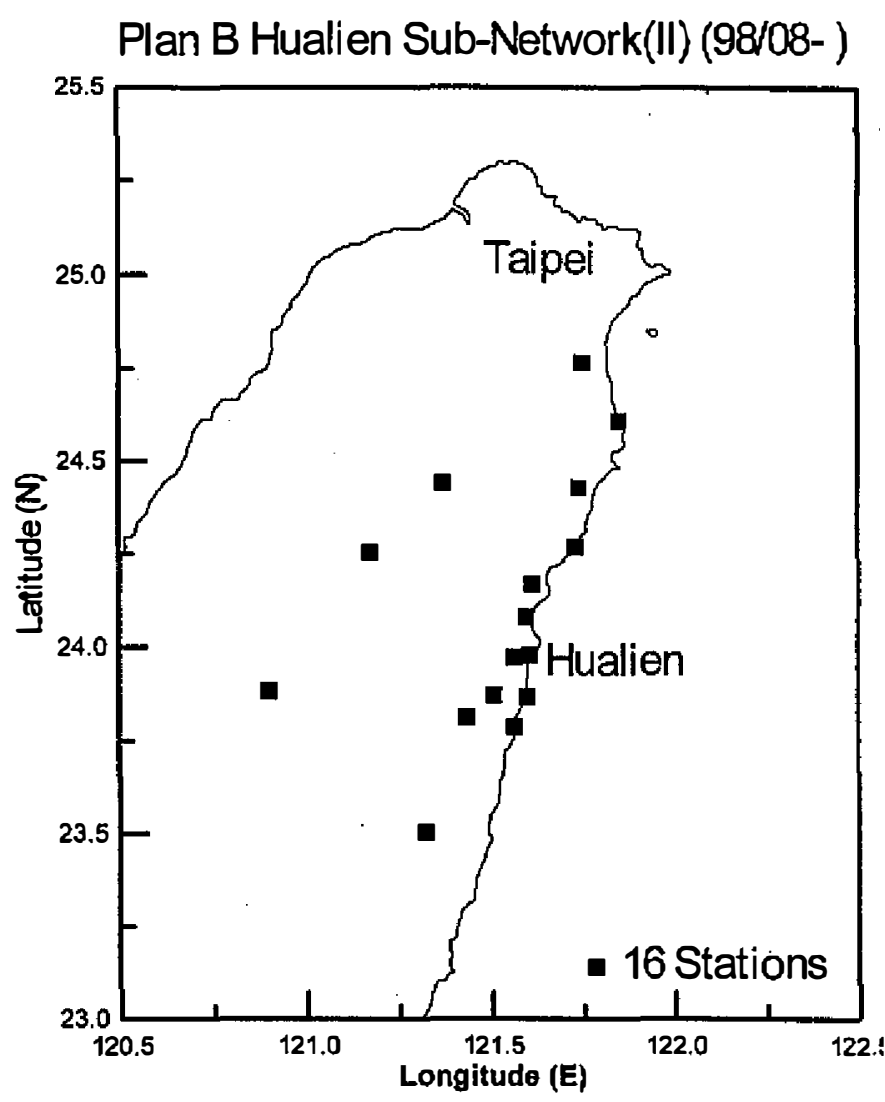

Fig. 7. Station distribution of the Plan B Hualien sub-network (II).

of $2 \mathrm{sec}$. Comparing with the Hualien sub-network (I), the reporting time is shorter, about 1 sec both in response time and in effective response time.

\subsection{Location}

As a comparison, the epicenters and focal depths of twenty-seven earthquakes listed in Table 3, as determined by the on-line system (Wu et al., 1998c) versus the off-line manual procedures, are shown in Fig. 8. The average difference in epicenter location is about $2 \mathrm{~km}$ with a standard deviation of $2 \mathrm{~km}$; the average difference in focal depth is about $0 \mathrm{~km}$ with a standard deviation of $3 \mathrm{~km}$. The result is significantly better than both the Plan A system and the Plan B Hualien sub-network (I).

\subsection{Magnitude}

Figure 9 shows the magnitude relationship of the twenty-seven earthquakes determined by this system and the off-line manual procedures. The magnitudes show a very good correlation. The magnitude difference varies from -0.2 to 0.2 unit, with average being 0 unit and a standard deviation of 0.1 unit. The results have significantly improved over both the Plan A system and the Plan B Hualien sub-network (I). 
Table 3. Parameters of twenty-seven events recorded by the Plan B Hualien subnetwork (II) determined from on-line and off-line procedures, during the period from August 1998 to April 1999, with magnitude ranging from 3.6 to 5.2 .

\begin{tabular}{|c|c|c|c|c|c|c|c|c|c|c|c|}
\hline \multirow{2}{*}{ Date } & \multirow{2}{*}{ Time } & \multicolumn{4}{|c|}{ Off-line (automatic) } & \multicolumn{4}{|c|}{ On-line (manual) } & \multirow{2}{*}{$\begin{array}{c}\mathrm{Tr} \\
(\mathrm{sec})\end{array}$} & \multirow{2}{*}{$\begin{array}{c}\text { Ter } \\
(\mathrm{sec})\end{array}$} \\
\hline & & Lat. (N) & Long. (E) & $\begin{array}{l}\text { Depth } \\
(\mathrm{km})\end{array}$ & $\mathrm{M}_{\mathrm{L}}$ & Lat. $(\mathrm{N})$ & Long (E) & $\begin{array}{l}\text { Depth } \\
(\mathrm{km})\end{array}$ & $\overline{M_{L}}$ & & \\
\hline $1998 / 08 / 08$ & $17: 49: 05.93$ & 24.01 & 121.59 & 28.04 & 4.51 & 24.03 & 121.53 & 26.81 & 4.36 & 16 & 11 \\
\hline $1998 / 09 / 04$ & $10: 40: 52.56$ & 23.92 & 121.50 & 12.57 & 5.07 & 23.92 & 121.51 & 13.77 & 4.92 & 15 & 12 \\
\hline $1998 / 09 / 21$ & $16: 29: 39.01$ & 23.92 & 121.49 & 13.03 & 4.64 & 23.93 & 121.5 & 13.81 & 4.68 & 17 & 14 \\
\hline 1998/09/29 & $07: 53: 26.81$ & 24.06 & 121.45 & 5.00 & 3.58 & 24.06 & 121.45 & 12.40 & 3.65 & 16 & 12 \\
\hline $1998 / 10 / 10$ & $21: 58: 38.60$ & 23.92 & 121.41 & 17.36 & 3.91 & 23.94 & 121.40 & 14.38 & 3.88 & 20 & 16 \\
\hline $1998 / 10 / 11$ & 04:56:35.19 & 23.97 & 121.62 & 52.40 & 4.62 & 23.98 & 121.61 & 50.09 & 4.59 & 25 & 16 \\
\hline $1998 / 10 / 13$ & 08:58:18.14 & 23.95 & 121.41 & 16.15 & 4.17 & 23.98 & 121.37 & 11.39 & 4.08 & 15 & 11 \\
\hline $1998 / 10 / 24$ & 18:18:45.72 & 23.92 & 121.52 & 14.68 & 3.60 & 23.92 & 121.52 & 14.75 & 3.56 & 16 & 13 \\
\hline 1998/11/03 & $09: 40: 46.29$ & 24.10 & 121.61 & 29.39 & 4.51 & 24.12 & 121.56 & 32.58 & 4.62 & 20 & 15 \\
\hline $1998 / 11 / 10$ & $04: 12: 25.75$ & 24.10 & 121.46 & 13.84 & 3.87 & 24.10 & 121.46 & 13.18 & 3.87 & 17 & 13 \\
\hline $1998 / 11 / 16$ & $04: 14: 31.91$ & 24.10 & 121.63 & 31.56 & 4.24 & 24.10 & 121.61 & 25.46 & 4.14 & 18 & 13 \\
\hline $1998 / 11 / 19$ & $10: 30: 04.66$ & 23.85 & 121.55 & 53.24 & 5.22 & 23.86 & 121.55 & 58.42 & 5.17 & 23 & 15 \\
\hline $1998 / 11 / 22$ & $05: 19: 08.22$ & 24.10 & 121.59 & 31.22 & 4.21 & 24.09 & 121.62 & 30.55 & 4.15 & 17 & 11 \\
\hline $1998 / 11 / 25$ & 20:22:09.46 & 23.99 & 121.58 & 11.49 & 3.65 & 24.00 & 121.58 & 11.65 & 3.66 & 16 & 13 \\
\hline $1998 / 12 / 04$ & 01:35:45.51 & 23.92 & 121.45 & 13.36 & 3.63 & 23.93 & 121.44 & 12.88 & 3.68 & 17 & 13 \\
\hline $1998 / 12 / 30$ & $17: 49: 56.61$ & 24.26 & 121.70 & 15.08 & 4.46 & 24.26 & 121.70 & 15.19 & 4.28 & 20 & 17 \\
\hline $1999 / 01 / 18$ & $15: 18: 00.19$ & 23.96 & 121.46 & 14.11 & 3.85 & 23.96 & 121.45 & 13.95 & 3.88 & 17 & 13 \\
\hline $1999 / 02 / 09$ & 19:11:07.81 & 23.94 & 121.41 & 17.13 & 4.63 & 23.93 & 121.42 & 16.57 & 4.68 & 17 & 13 \\
\hline $1999 / 02 / 12$ & $05: 26: 59.86$ & 24.15 & 121.64 & 31.96 & 4.02 & 24.16 & 121.66 & 36.25 & 4.21 & $2 !$ & 16 \\
\hline $1999 / 02 / 17$ & $00: 16: 07.47$ & 23.94 & 121.43 & 13.19 & 3.76 & 23.95 & 121.42 & 11.33 & 3.58 & 15 & 11 \\
\hline $1999 / 02 / 20$ & $10: 29: 57.82$ & 23.96 & 121.44 & 14.57 & 3.80 & 23.98 & 121.43 & 13.28 & 3.74 & 17 & 13 \\
\hline $1999 / 02 / 21$ & $00: 50: 32.51$ & 23.97 & 121.44 & 16.69 & 3.80 & 23.94 & 121.46 & 17.36 & 3.77 & 18 & 13 \\
\hline $1999 / 03 / 05$ & $09: 44: 52.72$ & 24.09 & 121.50 & 19.97 & 4.06 & 24.09 & 121.50 & 24.91 & 4.02 & 18 & 14 \\
\hline $1999 / 03 / 21$ & $14: 50: 25.78$ & 23.84 & 121.63 & 50.77 & 4.40 & 23.83 & 121.65 & 48.27 & 4.38 & 22 & 15 \\
\hline 1999/03/29 & $10: 28: 28.99$ & 23.93 & 121.63 & 13.22 & 3.75 & 23.94 & 121.62 & 13.87 & 3.77 & 14 & 11 \\
\hline $1999 / 04 / 02$ & $06: 12: 14.07$ & 23.97 & 121.44 & 16.48 & 4.01 & 23.98 & 121.42 & 10.66 & 3.86 & 16 & 12 \\
\hline $1999 / 04 / 10$ & $07: 52: 25.18$ & 24.11 & 121.64 & 11.27 & 4.84 & 24.11 & 121.62 & 13.58 & 4.83 & 17 & 14 \\
\hline
\end{tabular}

\section{DISCUSSION AND CONCLUSION}

Based on the methodology employed in the above systems, there is an inevitable trade-off between the reliability of earthquake information and the reporting time. To gain a shorter reporting time (and thus a longer warning time), one must use a very short initial section of the waveforms. This will be less reliable and probably will cause false alarms. For example, the Plan A system is faster in reporting but gives poor results. On the other hand, the Plan B Hualien sub-network (II) gives more reliable information by spending a longer time in data acquisition and processing. It is thus important to find an optimizing point.

Figure 10 shows the areas passed by the shear waves in eight seconds of recording time after system triggered for the twenty-seven events recorded by the Plan B Hualien sub-network (II). It essentially covers all the stations in Hualien area. Thus, a well-determined magni- 


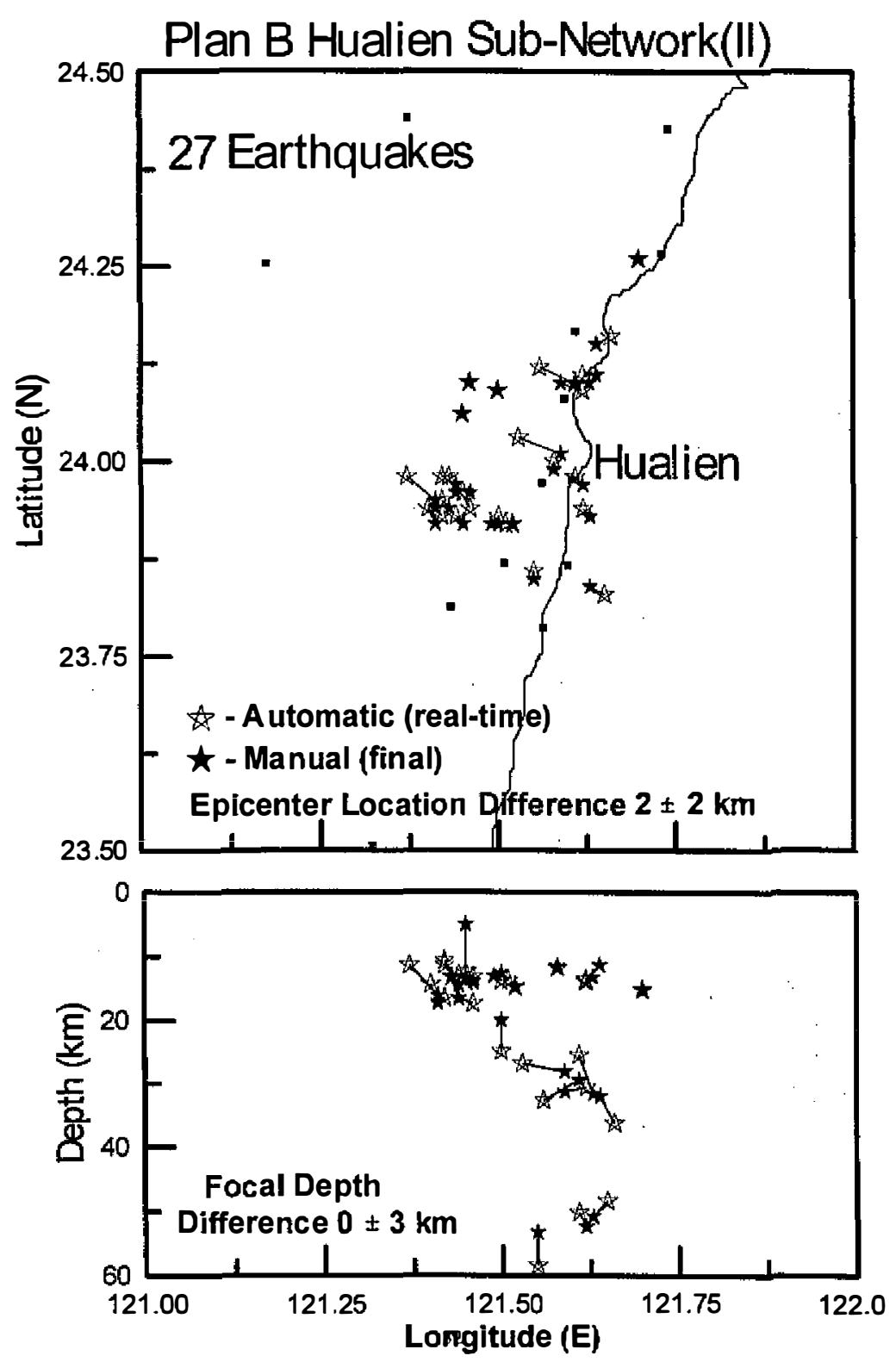

Fig. 8. Comparison of the automatic location and the manual location determined by the Plan B Hualien sub-network (II). The small solid squares are present the station location of this network.

tude can be expected by using almost all shear waves recorded by the stations in the network. In Fig. 11, the dashed line shows the Hualien network stations covered by shear waves of the twenty-seven events as recorded by the Plan B Hualien sub-network (II) with respect to the continuous recording time after the system triggered. This result shows that the station cover- 


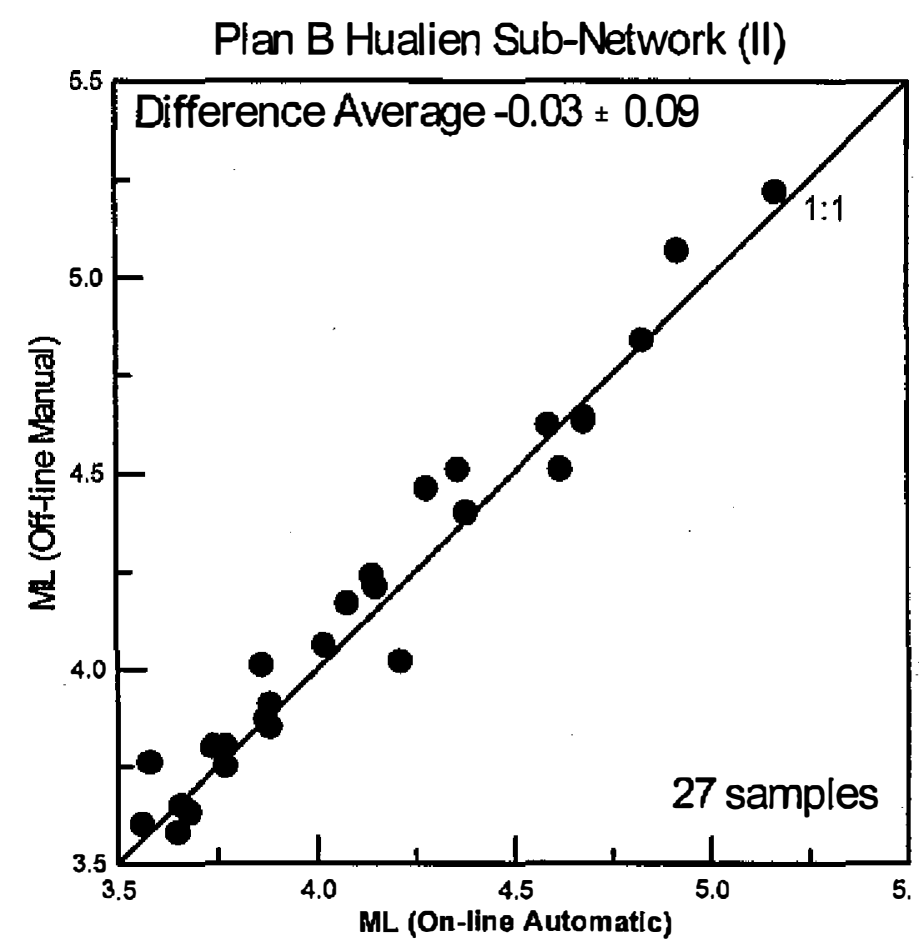

Fig. 9. Relationship between the automatic- determined magnitude and the manual-determined magnitude for twentyseven events recorded by the Plan B Hualien sub-network (II).

age almost reaches $100 \%$ (for all eight stations to record the shear waves) of continuous recording time in $8 \mathrm{sec}$. Then, if the continuous recording time is set to $5 \mathrm{sec}$, there will be about six stations (i.e., of $75 \%$ station coverage), which will record the shear waves completely. If we consider that six stations are enough to estimate the magnitude, we can gain $3 \mathrm{sec}$ earlier in reporting.

For the case of a larger earthquake, some distant stations will be triggered by the automatic phase picking process (due to reaching the threshold of the signal to noise ratio). The system may under-estimate magnitude value, since the $P$ waves reaches and triggers the distant stations, but the $S$ waves are not yet received. To avoid this problem, we can use only the first six stations to determine the magnitude, and thus decrease the continuous recording time of system from 8 to $5 \mathrm{sec}$. The Taipei metropolitan area will have about $20 \mathrm{sec}$ of early warning time if the event with the same location as the November 14, 1986 earthquake occurs. Most of the dense population areas in Taiwan will at least have $15 \mathrm{sec}$ of early warning time (Fig. 12) as indicated by this analysis.

We are encouraged in the development of earthquake early warning system based on the successful experience of the latest results of Plan B Hualien Sub-network (II) for the Hualien area earthquakes. The 13-sec average effective response time of the network will give about $15 \mathrm{sec}$ of early warming time at Taipei before the arrival of strong ground shaking. This system can be improved to about $18 \mathrm{sec}$ of early warning time in the future. However, the earthquake early warning information is not yet available for immediate public release in the current system. We realize that the release of an earthquake early warning will not produce social 


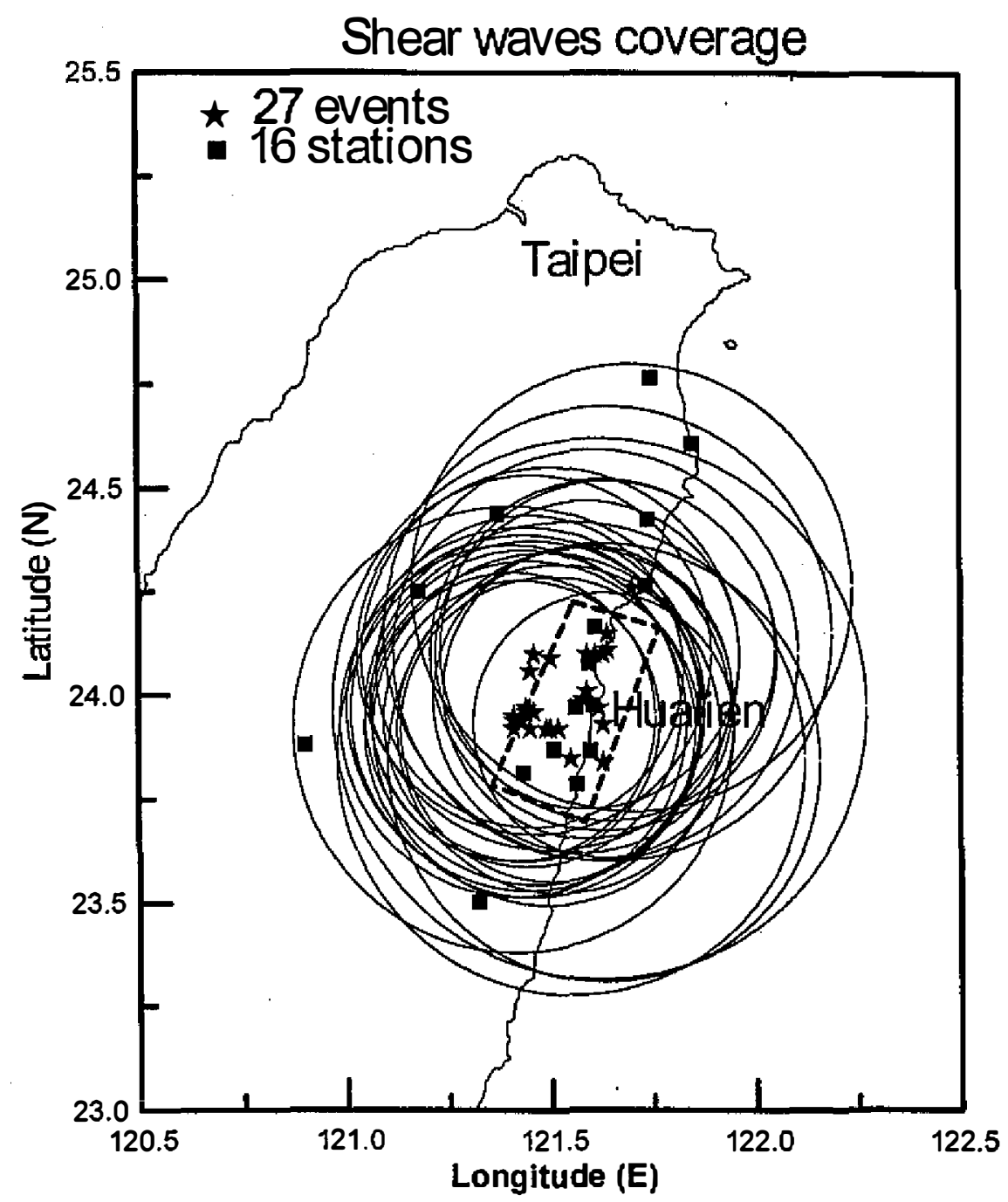

Fig. 10. Map to demonstrate the area passed by the shear waves in the eight seconds after the system has been triggered. Each circle indicates the front that shear waves reach to, with respect to an earthquake (solid start). The eight stations in the target area (dashed line) are used for early warning processing.

benefits unless there is a comprehensive program to educate the public on how to respond to a warning message.

Acknowledgments We wish to thank Prof. H. Kanamori and Prof. Y.-H. Yeh for reviewing this article and providing many thought-provoking comments. This research was supported by the National Science Council of the Republic of China under Grant No. NSC89-2625-Z-052015. 


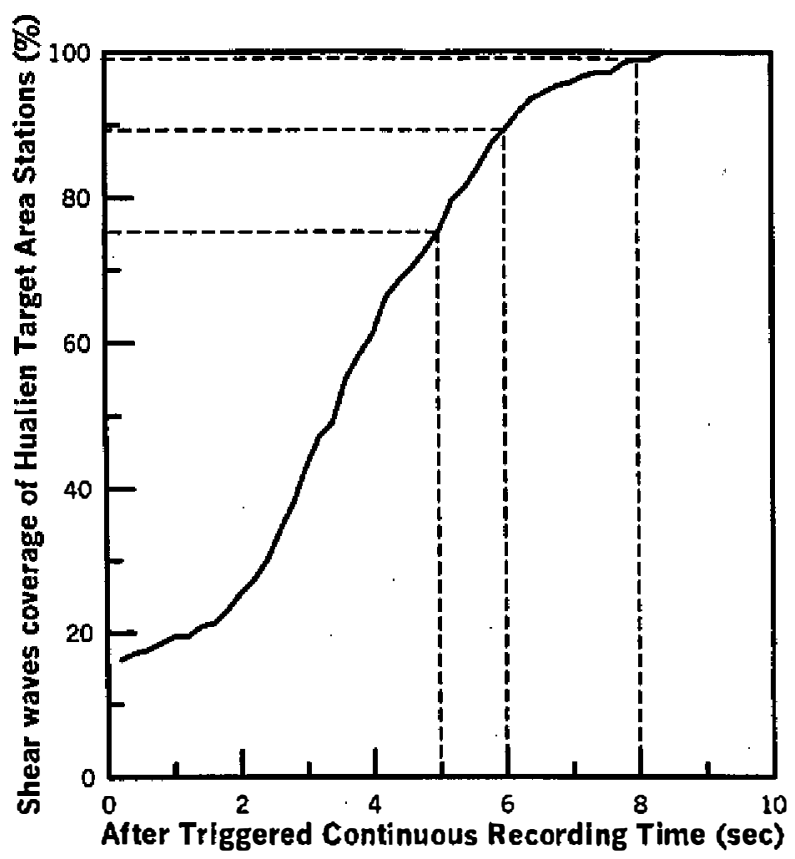

Calculated Early Warning Time of the Earthquake of Nov 14, 1986 (ML6.8)

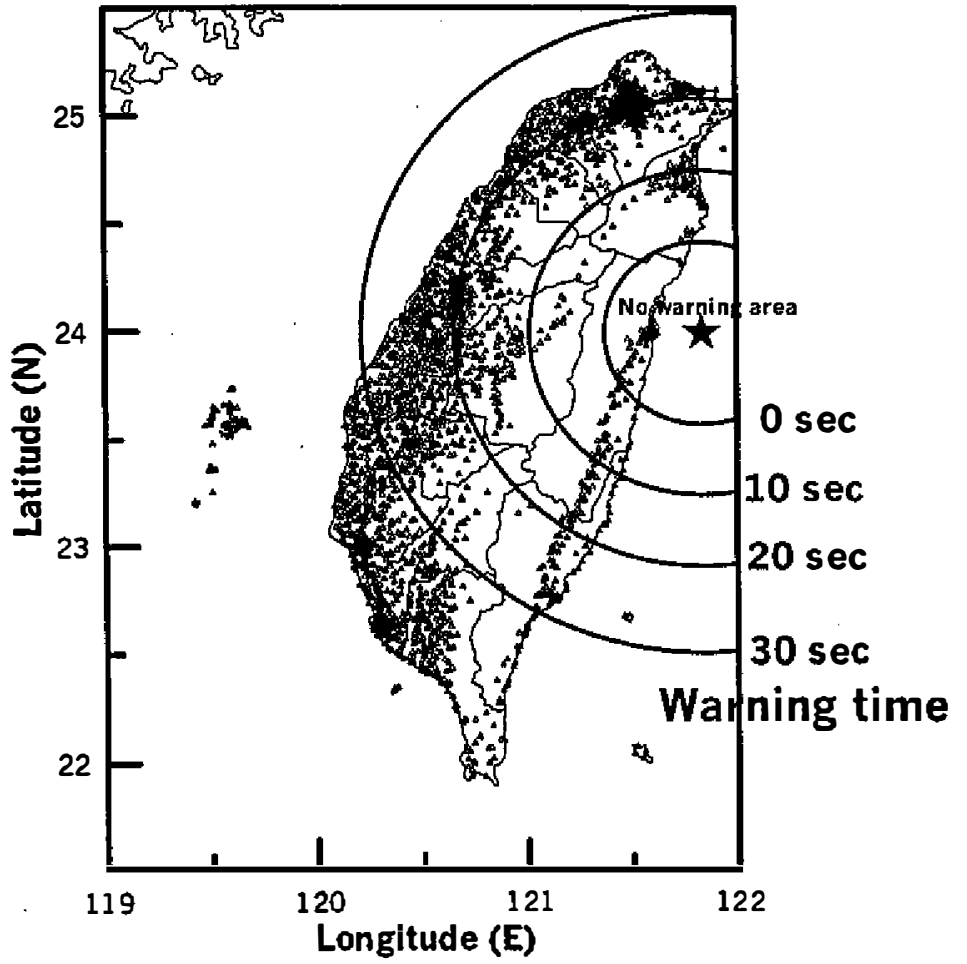

Fig. 11. Relationship between the continuous recording time and the ratio of the total number of stations that record the shear wave of the specified stations in the target area for all the twentyseven events.

Fig. 12. Expected early waming time for the earthquake of 14 November, 1986 as indicated by this analysis. The triangles present the locations of the elementary schools. 


\section{REFERENCES}

Chung, J. K., W. H. K. Lee, and T. C. Shin, 1995: A prototype earthquake waming system in Taiwan: operation and results. IUGG XXI General Assembly, Abstracts Week A, p A406.

Kanamori, H., E. Hauksson, and T. Heaton, 1997: Real-time seismology and earthquake hazard mitigation. Nature, 390, 461-464.

Lee, W. H. K. (Editor), 1994: "Realtime Seismic Data Acquisition and Processing". IASPEI Software Library, Vol. 1 (Second Edition)", Seismological Society of America, El Cerrito, CA.

Lee, W. H. K., T. C. Shin, and T. L. Teng, 1995: Design and implementation of earthquake waming systems in Taiwan. IUGG XXI General Assembly, Abstracts Week A, p A406.

Lee, W. H. K., T. C. Shin, and T. L. Teng, 1996: Design and implementation of earthquake early warning system in Taiwan. Paper No. 2133, 11 th World Conference of Earthquake Engineering, Acapulco, Mexico.

Lee, W. H. K., T. C. Shin, T. L. Teng, Y. B. Tsai, and Y. M. Wu, 1997: Results of the Taiwan Rapid Earthquake Information System. AGU Fall Meeting, San Francisco, USA.

Shin, T. C., Y.B. Tsai, and Y. M. Wu, 1996: Rapid response of large earthquakes in Taiwan using a real-time telemetered network of digital accelerographs. Paper No. 2137, 11th World Conference of Earthquake Engineering, Acapulco, Mexico.

Teng, T. L., L. Wu, T. C. Shin, Y. B. Tsai, and W. H. K. Lee, 1997: One minute after: strongmotion map, effective epicenter, and effective magnitude. Bull. Seism. Soc. Am., 87, 1209-1219.

Wu, Y. M., C. C. Chen, T. C. Shin, Y. B. Tsai, W. H. K. Lee, and T. L. Teng, 1997a: Taiwan Rapid Earthquake Information Release System. Seism. Res. Lett., 68, 931-943.

Wu, Y. M., T. C. Shin, J. K. Chun, Y. B. Tsai and C. C. Chen, 1997b: Toward a 30-seconds rapid earthquake information system in Taiwan. $29^{\text {th }}$ IASPEI meeting, Thessaloniki, Greece.

Wu, Y. M., C. C. Chen, T. C. Shin, and Y. B. Tsai, 1998a: An evaluation of the Taiwan rapid earthquake information release system (in Chinese). Meteorol. Bull., 42, 16-28.

Wu, Y. M., C. C. Chen, J. K. Chung, and T. C. Shin, 1998b: An automatic phase picker of the real-time acceleration seismic network (in Chinese). Meteorol. Bull., 42, 103-117.

Wu, Y. M., T. C. Shin, and Y. B. Tsai, 1998c: Quick and reliable determination of magnitude for seismic early warning. Bull. Seism. Soc. Am., 88, 1254-1259.

Wu, Y. M., J. K. Chung, C. C. Chen, T. C. Shin, and Y. B. Tsai, 1998d: An approach of earthquake information rapid reporting by using a sub-network (Hualien) (in Chinese). Meteorol. Bull., 42, 331-342.

Wu, Y. M., 1999: Development of real-time earthquake reporting and warning systems-Taiwan experience. Ph.D. dissertation of Institute of Geophysics, National Central University, $152 \mathrm{pp}$.

Yeh, Y. H., C. H. Chen and T. L. Teng, 1988: Study on focusing of seismic wave energy in Taipei basin: I. A dynamic ray-tracing approach, Proceedings of the CCNAA-AIT Joint Seminar on Research for Multiple Hazards Mitigation, Taipei, Taiwan, 107-120. 